\title{
Development of experimental in vitro burn model ${ }^{1}$
}

\author{
Ana Carolina Morais Fernandes ${ }^{\mathrm{I}}$, Jerônimo Pereira de França ${ }^{\mathrm{II}}$, Silvana Gaiba ${ }^{\mathrm{III}}$, Antonio Carlos Aloise ${ }^{\mathrm{IV}}$, Andrea Fernandes de

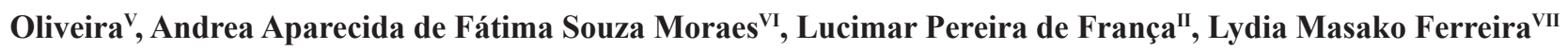

DOI: http://dx.doi.org/10.1590/S0102-86502014001400004

IMD. Resident, Burn Care Unit, Plastic Surgery Division, Universidade Federal de São Paulo, São Paulo, SP, Brazil. Technical procedures.

IIPhD, Associate Professor, Department of Biological Sciences, Universidade Estadual de Santa Cruz, Ilhéus-BA, Brazil. Scientific and intellectual content of the study, interpretation of data and critical revision.

IIIPhD, Fellow Pos-PhD degree, Department of Biological Sciences, Universidade Estadual de Santa Cruz, Ilhéus-BA, Brazil. Technical procedures, acquisition and interpretation of data, manuscript writing.

${ }^{\text {Iv }} \mathrm{PhD}$, Fellow Pos-PhD degree, Plastic Surgery Division, Universidade Federal de São Paulo, São Paulo, SP, Brazil. Interpretation of data and critical revision.

vPhD, Fellow PhD degree, Plastic Surgery Division, Universidade Federal de São Paulo, São Paulo, SP, Brazil. Interpretation of data and critical revision.

vIPhD, Department of Biological Sciences, Universidade Estadual de Santa Cruz, Ilhéus-BA, Brazil. Technical procedures.

VIIHead and Full Professor, Plastic Surgery Division, UNIFESP, Researcher 1A-CNPq, Director Medicine III-CAPES, Sao Paulo-SP, Brazil. Interpretation of data and critical revision.

\section{ABSTRACT}

PURPOSE: To propose an experimental burn model in NIH-3T3 cell line.

METHODS: Induction of thermal injury in cultures of mouse fibroblast - NIH-3T3- cell line and determination of cell viability by MTT and imunofluorescence.

RESULTS: The heating of the Petri dish increased proportionally to the temperature of the base and the time of exposure to microwave. In this in vitro burn model, using the cell line NIH-3T3 was observed drastic cellular injury with significant changes in cell viability and activity. It showed drastically modified cell morphology with altered membrane, cytoskeleton and nucleus, and low cellularity compared to the control group.

CONCLUSION: The burn model in vitro using the cell line NIH-3T3 was reproductive and efficient. This burn model was possible to determine significant changes in cell activity and decreased viability, with drastic change in morphology, cell lysis and death.

Key words: Burn; fibroblast; cell line NIH-3T3; microwave; MTT; Confocal microscopy. 


\section{Introduction}

Burns are responsible for many pathophysiological changes $^{1-3}$, represents a severe form of trauma ${ }^{3,4}$. Although there are many advances in knowledge of burn care, treatment is still suboptimal, because there is still lack of studies based on evidence ${ }^{5}$.

In order to add knowledge about the pathophysiology and possible therapeutic agents in burns several experimental models can be applied: cell and tissue culture for studies of therapeutic agents mechanism of action and burned tissue substitutes; animal models to evaluate efficacy of therapeutic agents and in vivo study of biological phenomena - and thus allow clinical trials after verification of security aspects ${ }^{6,7}$.

In experimental in vivo models it is difficult to characterize molecular changes by thermal burns at the cellular level in isolation, since there are many variables involved. Due to the systemic response by thermal injury, especially inflammatory and coagulation cascades, it is difficult to assess only the cellular effect produced by direct stimulation ${ }^{8}$.

The objective of this study is to propose an experimental burn model of cultured fibroblasts.

\section{Methods}

\section{Cell culture}

Mouse fibroblast cell line NIH-3T3 was purchased from ATCC (American Type Culture Collection CRL-1658, Manassas, VA, USA). The cells were maintained at $37{ }^{\circ} \mathrm{C}$ in an incubator with a humidified atmosphere of $5 \% \mathrm{CO}_{2}$ and $95 \% \mathrm{O}_{2}$ and cultured in Dulbecco's modified eagle's medium (DMEM) with 10\% fetal bovine serum (FBS) (Gibco, Grand Island, NY, USA), Gentamicin at $50 \mu \mathrm{g} / \mathrm{mL}$ (Gibco, Grand Island, NY, USA), Amphotericin B at $50 \mu \mathrm{g} /$ mL (Biolab, São Paulo, SP, Brasil), (Figure 1).

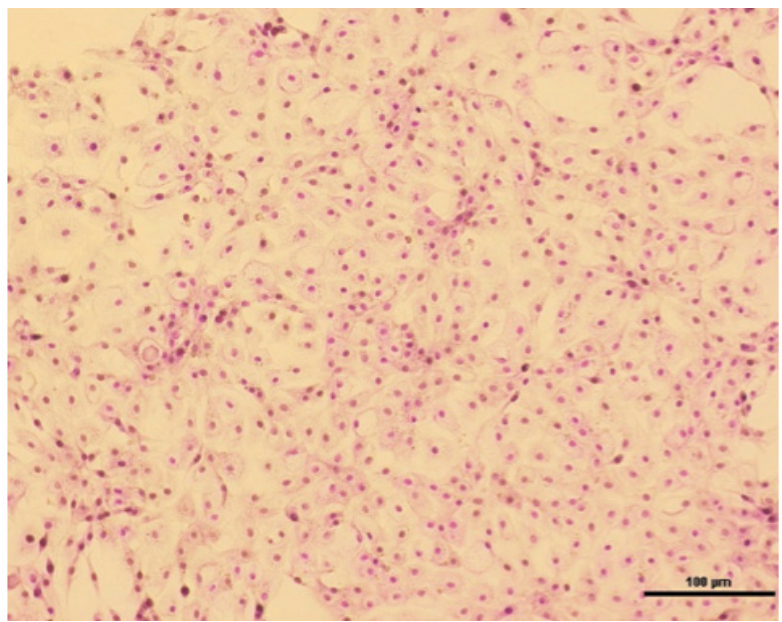

FIGURE 1 - Mouse fibroblast cell line NIH-3T3 culture on culture dish.

\section{Burn in vitro model}

Under sterile conditions inside a laminar flow the thermal injury was induced in vitro cells using a base of glass plate heated by a microwave oven (Brastemp BMA30A). The cell cultures (Culture dishes) were exposed to thermal injury (burn) by contact with the pre-heated base of glass at a specified temperature (Base inicial temperature $-\mathrm{T}_{\text {initial }}$ base) in a microwave oven. The medium from the culture plates (Culture dishes) was aspirated and immediately them initial temperature (Dish inicial temperature $\mathrm{T}_{\text {initial }}$ dish) was determined. Then the bottom of the culture dish was placed in contact with the base of glass for 30 seconds (Figure 2). After induction of the burn, the final temperature of the base ( $\mathrm{T}_{\text {final }}$ base) and final temperature of the dishes $\left(\mathrm{T}_{\text {final }}\right.$ dish) were measured, and culture medium at $4{ }^{\circ} \mathrm{C}$ was added to decrease the temperature of the hot dish to stop the burning process.

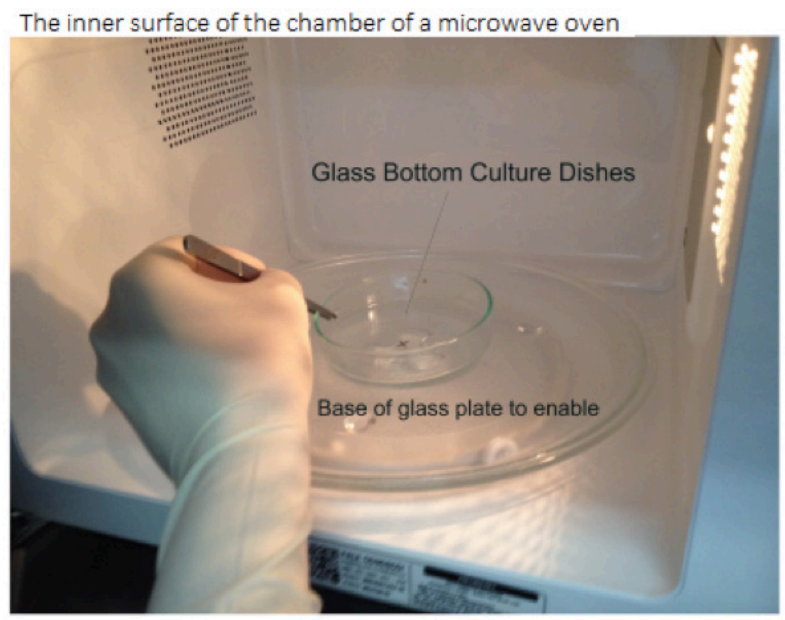

FIGURE 2 - Heating of the base of glass to enabe the heat transfer to the cell culture dishes.

\section{Heating of the base of glass}

The heating of the base of glass with thermal capacity $\left(\mathrm{CV}=100.17 \mathrm{cal} / \mathrm{g} .{ }^{\circ} \mathrm{C}\right)$ was performed using a microwave oven with potency of $400 \mathrm{~W}$ or $400 \mathrm{~J} / \mathrm{s}$, as shown in Figure 3.

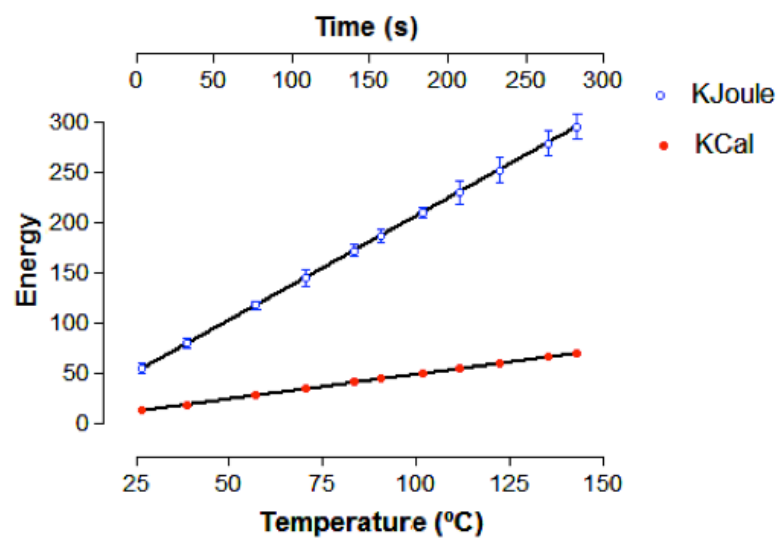

FIGURE 3 - Heat of the base of glass and heat transfer to the dishes with $3 \mathrm{~T} 3$ line cell culture. 
Figure 4 shows the changes in the temperature in the base of glass and the $3 \mathrm{~T} 3$ cell culture dishes with thermal capacity $\mathrm{Cvc}$ $=8.5917 \mathrm{cal} / \mathrm{g} \cdot{ }^{\circ} \mathrm{C}$, after a contact time of 30 seconds.

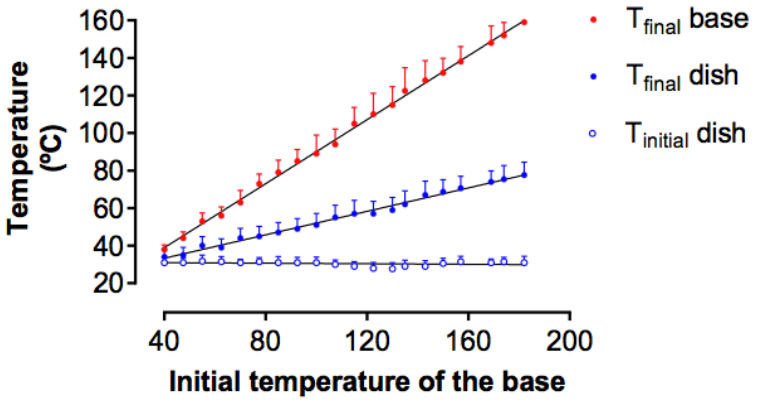

FIGURE 4 - Increase of the temperature of 3T3 culture dish following the transfer of heat from the base of glass to the culture dishes after a contact time of 30 seconds.

\section{Effect of increased temperature on NIH-3T3 cell Viability}

\section{Cell viability assay}

The effects of thermal injury on cell viability were determined by MTT assay, which is based on the reduction of a tetrazolium salt by mitochondrial dehydrogenase in viable cells. For all experimental groups cells were seeded, after tripsinization and resuspension in medium (DMEM) with Gentamicin at $50 \mu \mathrm{g} /$ $\mathrm{mL}$ (Gibco, Grand Island, NY, USA) and Amphotericin B at 50 $\mu \mathrm{g} / \mathrm{mL}$, in $96-w e l l$ plates at a density of $1 \times 10^{4}$ cells $/$ well. Then $50 \mu \mathrm{L}$ of MTT $10 \%(0.5 \mathrm{mg} / \mathrm{mL})$ was added to each well to reach a total reaction volume of $100 \mu \mathrm{L}$ and the plates were incubated for 2h. Figure 5-A represents NIH-3T3 line cells containing formazan crystals after $2 \mathrm{~h}$ incubation in MTT. Figure 5-B represents an expanded image where formazan crystals can be observed.

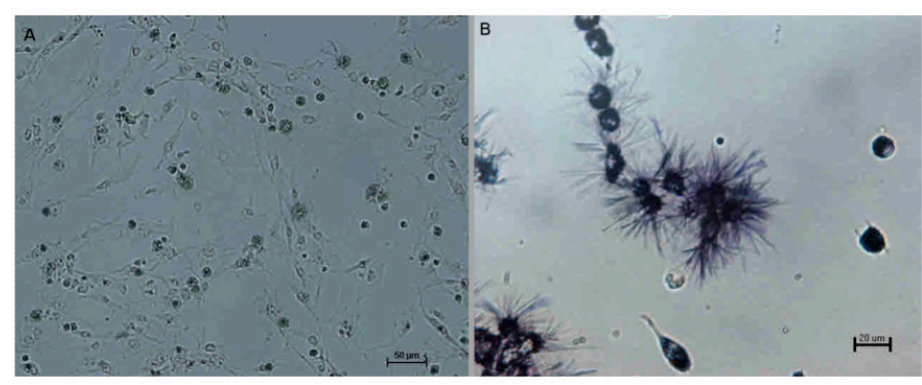

FIGURE 5 - A- NIH-3T3 cells $2 \mathrm{~h}$ after incubation in MTT. B- Expanded image shows the formazan crystals.
The resulting formazan crystals were dissolved in $100 \mu \mathrm{L}$ isopropyl alcohol. Absorbance was measured at $570 \mathrm{~nm}$ using a colorimetric MTT ELISA assay (VERSAmax Tunable microplate reader, Molecular Devices, CA, USA), (modified method of Zeng et $\left.a l .{ }^{9}\right)$. All the experiments were thrice repeated and sample analyses were performed in quadruplicate.

\section{Immunofluorescence labeling}

The NIH-3T3 cells were plated on glass coverslips, fixed in $0.4 \%$ paraformaldehyde for $30 \mathrm{~min}$ at $4{ }^{\circ} \mathrm{C}$, washed 3 times in PBS. The cells were stained with CellMask ${ }^{\mathrm{TM}}$ Deep Red plasma membrane stain, (1:1000), Molecular Probe life technologies, incubation was performed in PBS containing $10 \%$ normal bovine serum for $40 \min$ at $22{ }^{\circ} \mathrm{C}$, washed 3 times in PBS. Cells were then, permeabilized with $0.1 \%$ saponin in PBS containing $10 \%$ normal bovine serum for $30 \mathrm{~min}$ at $22{ }^{\circ} \mathrm{C}$ and stained with a combination of fluorescent dyes. Actin filaments $F$ of cytoskeleton were immunostained with phalloidin conjugated with Alexa Fluor 488 (green), Molecular Probe life technologies. Phalloidin (1:500) incubation was performed in PBS containing 10\% normal bovine serum and $0.1 \%$ saponin. Nuclei were counter-stained with blue fluorescent DNA stain DAPI (1:1000), Molecular Probe life technologies, for $10 \mathrm{~min}$ at $22^{\circ} \mathrm{C}$. The images are a composite of 3 images acquired using filter sets appropriate for blue, green and red fluorescence, on a Confocal Laser Scanning Microscope Leica - TCS SP8 (Germany) as adapted from Gaiba et al. (2012).

\section{Statistical analysis}

Data are presented as mean $\pm \mathrm{SD}$ of four independent experiments. Statistical analysis among groups was performed by one-way analysis of variance (ANOVA) followed by the NewmanKeuls Multiple Range Test. GraphPad Prism v.3.0 software was used, $\mathrm{p}<0.05$ was considered to be statistically significant.

\section{Results}

The MTT test allowed the determination of two graphics curves (two phases), that show an inflection point for the delta temperature of $15^{\circ} \mathrm{C}$ (Figure 6).

Morphological analysis of the control group by confocal microscopy (Figure 7). 

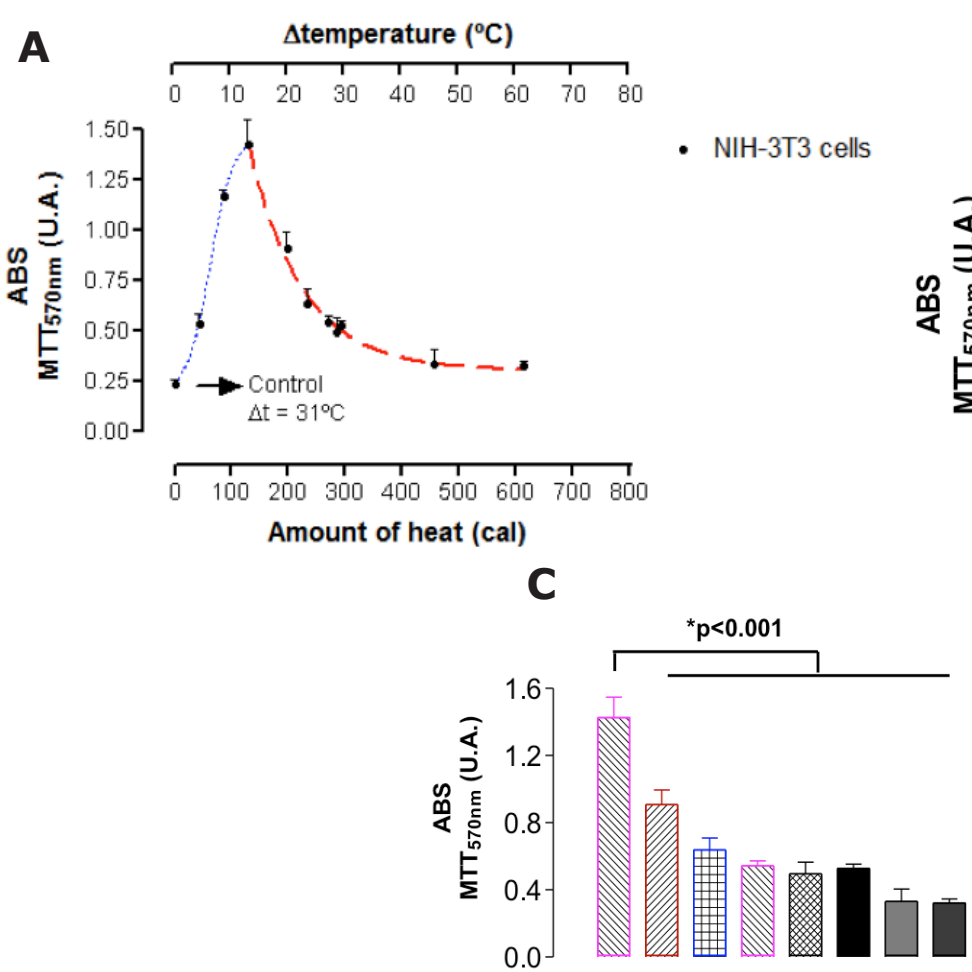

B

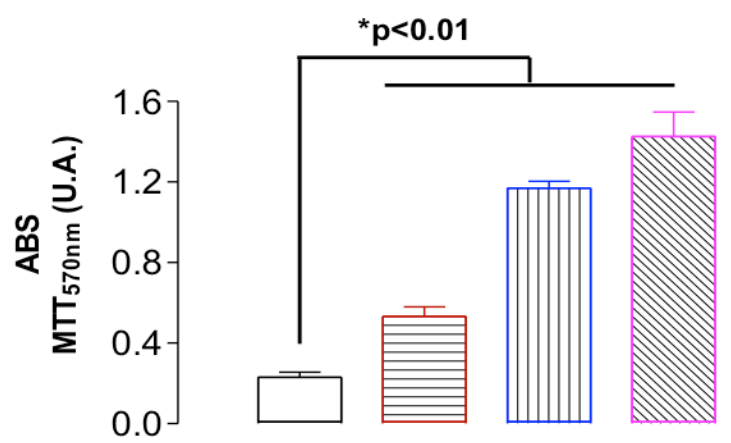

FIGURE 6 - The effects of thermal injury on cell viability determined by MTT assay. A- Represents the MTT assay that determinated two graphics curves (two phases) with an inflection point for the delta temperature of $15^{\circ} \mathrm{C}$. B- Blue line, represents the first phase (up) and the statistic difference of the experimental groups compared to the control group. C- Red line, represents the second phase (down) and the statistic difference of experimental groups compared to the inflection point.
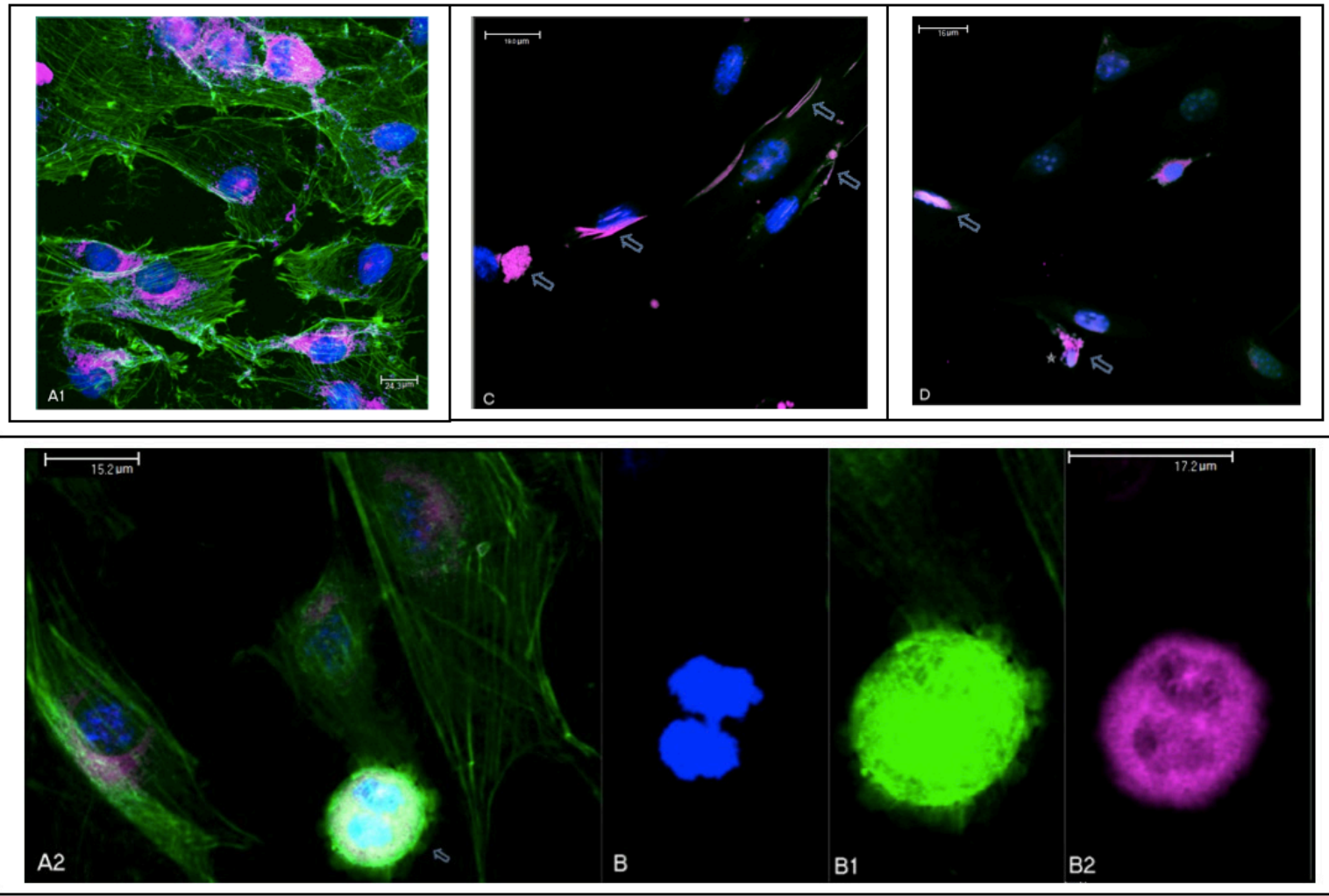

FIGURE 7 - Fluorescence microscopy image of NIH-3T3 cells control and after effects of thermal. Experimental Groups CG: (A1, A2) and microscopy with extended depth of field (B, B1 e B2) and after Heating of the base of glass plate to enabe to heat transfer to the glass botton culture dishes: (C e D). The cells were stained with CellMask ${ }^{\mathrm{TM}}$ Deep Red plasma membrane stain and location of the cell nuclei stained with DAPI (blue) and actin filaments making up the cytoskeleton labeled phalloidin conjugated to Alexa-Fluor 488 (green), overlap of images (A1, A2, C and D). DAPI staining was performed. Arrows (figure C and D) indicate the cells with DNA fragmentation and membrane blebbing. The star (figure A2) indicates pyknotic nuclei. Arrows (figure A2) indicate the cell division (mitosis) and microscopy with extended depth of field (B, B1 e B2). These images are representative of 5 replicates and 04 independent experiments. 


\section{Discussion}

Burn process is difficult to study in vivo both in human and animal models. In vitro models have proved to be a valuable tool in the study of skin pathophysiology ${ }^{10,11}$. The exclusion of systemic variables makes the model feasible and repeatable and therefore provides a way to study the cellular and molecular alterations in the burn process ${ }^{12}$.

In the literature there are not many in vitro burn experimental models, and none evaluated morphological changes or cell activity and viability.

The burn in vitro model using the NIH $3 \mathrm{~T} 3$ cell line (Figure 1), under sterile conditions (Figure 2) was reproductive and efficient, allowing to analyze the effect of heat transfer to the base of glass-culture dishes (Figure 3). The process efficiency was achieved by the high thermal capacity of the material (glass) and mainly by the thermal capacity of the glass base that exceed $11 x$ the thermal capacity of the culture plate, allowing the short time of 30 seconds in heat transfer without significant loss of thermal energy.

A high and constant power of the microwave oven is suitable for heating the glass plate, it is observed that the thermal energy (E) increased proportionally to the temperature and the exposure time to microwave (Figure 3 ). The linearity of the heating curves and the base of the culture plate after heat transfer from the base stated proportionality of the graphic curves corresponding to contact time (Figure 4). In this model it was possible to get in vitro burn lesion, promote cellular injuries with features and significant changes in cellular activity and viability observed by the MTT assay. The MTT assay, Figure 6, allowed the determination of two graphics curves (two phases) that show an inflection point for the delta temperature of $15^{\circ} \mathrm{C}$. These results suggest for the first phase (up) an increase in cellular activity as a linear function of temperature $\left(\mathrm{r}^{2}=0.98\right)$ to the point of inflection $\left(\mathrm{T}=15^{\circ} \mathrm{C}\right)$ and then a second exponential decay phase of decrease $\left(r^{2}=0.98\right)$ until saturation from delta temperature of $46^{\circ} \mathrm{C}$, with a significant decrease in cell viability by heat transfer.

Morphological analysis of cells in the control group showed high cellularity, irregular distribution of cells and formation of characteristic cluster growth of NIH-3T3 line cells; it was also observed extensive cellularity, maintained integrity of the cell nucleus and cytoskeleton and large numbers of cells in mitosis. However, exposed to different delta temperature it was observed drastic decrease in number of cells with large amount of fragmented cells, changes in the structure of the membrane and cytoskeleton (blebbing formation), presence of irregular and pyknotic nuclei and a reduction of number of cells in mitosis, as seen in Figure 7.

\section{Conclusions}

The in vitro burn model using the NIH-3T3 line cells was reproductive and efficient. In this model it was possible to get in vitro burns that promoted cellular injuries and significant changes in cellular activity and viability observed by the MTT assay. Also in this model burned cells showed a drastically modified morphology compared to the control group.

\section{References}

1. Ashburn MA. Burn pain: the management of procedure-related pain. J Burn Care Rehabil. 1995;16(3 Pt2):365-71.

2. Rosenkranz KM, Sheridan R. Management of the burned trauma patient: balancing conflicting priorities. Burns. 2002;28(7):665-9.

3. Summer GJ, Puntillo KA, Miaskowski C, Green PG, Levine JD. Burn injury pain: the continuing challenge. J Pain. 2007;8(7):533-48.

4. Hawkins A, Maclennan PA, McGwin Jr G, Cross JM, Rue LW, 3rd. The impact of combined trauma and burns on patient mortality. $\mathrm{J}$ Trauma. 2005;58(2):284-8.

5. Iurk LK, Oliveira AF, Gragnani A, Ferreira LM. Evidências no tratamento de queimaduras. Rev Bras Queimaduras. 2010;9(3):95-9.

6. Brigham PA, McLoughlin E. Burn incidence and medical care use in the United States: estimates, trends, and data sources. J Burn Care Rehabil. 1996;17(2):95-107.

7. Ferreira LM, Hochman B, Barbosa MV. Experimental models in research. Acta Cir Bras. 2005;20(Suppl 2):28-34.

8. Sobral CS, Gragnani A, Cao X, Morgan JR, Ferreira LM. Human keratinocytes cultured on collagen matrix used as an experimental burn model. J Burns Wounds. 2007;7:e6.

9. Zeng JZ, Zhang LK, Wang HX, Lu LQ, Ma LQ, Tang CS. Apelin protects heart against ischemia/reperfusion injury in rat. Peptides. 2009;30(6):1144-52.

10. Diegelman RF, McCoy BJ, Cohen IK. Growth kinetics and collagen synthesis by keloid fibroblasts in vitro. J Cell Physiol 1979; 98:341-6.

11. McCoy BJ, Cohen IK. Effect of cellular aging and density on cell growth and collagen synthesis in keloid and normal fibroblasts. In vitro. 1982;18:79-86.

12. Emanuelsson P, Kratz G. Characterization of a new in vitro burn wound model. Burns. 1997;23(1):32-6. 
Fernandes ACM et al.

\section{Acknowledgements}

To Prof. Helena Bonciani Nader responsible for the laboratory, Multiuser, Molecular Biology, UNIFESP and Prof. Ismael Dale Cotrim Guerreiro da Silva, Laboratory of Molecular Gynecology, UNIFESP.

\section{Correspondence:}

Lydia Masako Ferreira

Disciplina de Cirurgia Plástica-UNIFESP

Rua Napoleão de Barros, $715 / 4^{\circ}$ andar

04042-002 Sao Paulo - SP Brasil

Tel.: (55 11)5576-4118

Fax: (55 11)5571-6579

sandra.dcir@epm.br

jeronimopf@gmail.com

Financial source: National Council for Scientific and Technological Development (CNPq)

IResearch performed at Skin Cell Culture Laboratory, Plastic Surgery Division, Department of Surgery, Federal University of Sao Paulo (UNIFESP), Brazil. 